\title{
Calcifying Nested Stromal-Epithelial Tumour of the Liver: case report and review of literature
}

Nesreen Magdy ${ }^{1,2^{*}}$, Bassant Ahmed ${ }^{1,2}$ and Amira Elwy ${ }^{2,3}$

${ }^{*}$ Correspondence: Nesreen.magdy@nci.cu.edu.eg

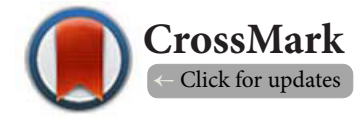

${ }^{1}$ Histopathology department, National Cancer Institute, Cairo University, Egypt. ${ }^{2}$ Histopathology department, Shefa Al-Orman Oncology Hospital, Luxor, Egypt.

${ }^{3}$ Histopathology department, South Egypt Cancer Institute, Assiut University, Egypt.

\begin{abstract}
Calcifying nested stromal-epithelial tumour (CNSET) of the liver is a rare tumour, recently included in the WHO Classification of Digestive system Tumours 2019. Its hallmark is the nested proliferation of epithelial and spindle cells with surrounding desmoplastic stroma, calcifications and ossifications. Less than 40 cases have been reported, whereas none has been reported in Middle Eastern descendants. We report the first case of CNSET in a 22-year-old Egyptian lady with detailed histological and clinical data.
\end{abstract}

Keywords: CNSET, Mesenchymal tumours, Liver

\section{Background}

Calcifying nested stromal-epithelial tumour (CNSET) is a rare, low grade hepatic neoplasm that was recently included in the WHO Classification of Digestive system Tumours 2019 [1]. It was first described by Ishak et al in 2001 [2]. CSET is considered a non-hepatobiliary tumour [3] of an uncertain lineage, and is characterized by a distinctive nested architecture of epithelioid and spindle cells, surrounded by cellular myofibroblastic stroma, and calcification [1].

Less than 40 cases have been reported with detailed clinical and pathologic data [7]. None has been reported in Middle Eastern descendants. We report the first case of CNSET in a 22-year-old Egyptian lady with detailed histological and clinical data. To the best of our knowledge, this is the $39^{\text {th }}$ reported case of CNSET.

\section{Case presentation}

A 22-year-old young lady presented to our hospital with right hypochondrial pain for one month. Post contrast tri-phasic CT showed a right hepatic focal lesion, $6.5 \times 9 \mathrm{~cm}$, with calcification, no significant contrast enhancement, and no extra-capsular extension or infiltration of extra-hepatic structures. No intrahepatic or venous channel dilatation. Tumour markers (CEA, CA15.3, CA125 and AFP) were normal. Exploration and surgical resection was done.

On gross examination, a non-cirrhotic hepatic segment
$12 \times 10 \times 7 \mathrm{~cm}$, weighing 270 grams, showed a non-capsulated fairly defined, lobulated rubbery, solid, homogeneous, tan whitish mass $10 \times 8.5 \times 5.5 \mathrm{~cm}$, with central hard bony area $3 \times 3$ $\mathrm{cm}$ (Figure 1). Microscopic examination (Figure 2) showed nests of spindle and epithelioid cells, surrounded by a cellular stroma entrapping proliferating bile ducts. Tumour cells were blastema-like to large epithelioid with ovoid nuclei, and low mitotic activity (1-3/ 10 HPFs). Areas of osseous metaplasia were seen. Neither tumour necrosis nor vascular invasion was seen. Immunostaining (Figure 3) revealed positive reaction for synaptophysin, INI-1, Beta catenin (nuclear and cytoplasmic), CK (epithelioid cells), vimentin, WT-1 and PR, but negative for AFP, HepPar-1, CD99, GFAP, SMA (stains the surrounding stroma) and chromogranin A. CK7 was negative in tumour cells, but stained the proliferating bile ducts. Ki67 labeling index was low $(<5 \%)$. The patient did not receive any adjuvant treatment and is under follow-up for 15 months and is disease free.

\section{Discussion and conclusion}

Calcifying nested stromal-epithelial tumour is a rare low grade hepatic neoplasm that predominates in females, with a male to female ratio of $1: 2.5$. It is more common in children and young adults, with an age range between 2 and 34 years $[8,9]$.

Despite most of reported CNSET cases are sporadic [1], yet some cases were reported to be associated with cortisol-related syndrome and rarely, Beckwith-Wiedemann syndrome (BWS) [4]. 
Magdy et al., Journal of Histology \& Histopathology 2020,

The majority of cases have been discovered incidentally, with occasional cases presented with abdominal pain or mass [5]. Liver function tests, serum a-fetoprotein [AFP] and carcinoembryonic antigen [CEA] are typically within normal ranges [6]. CNSET is a tumour of uncertain histogenesis [7]. An epithelial origin with mesenchymal differentiation has been proposed [10], however another study stated that expression of WT1suggests a mesenchymal to epithelial phenotype [11].

Hepatoblastomas (HB) is an important differential diagnosis for CNSET [12]. Distinguishing features include high AFP serum
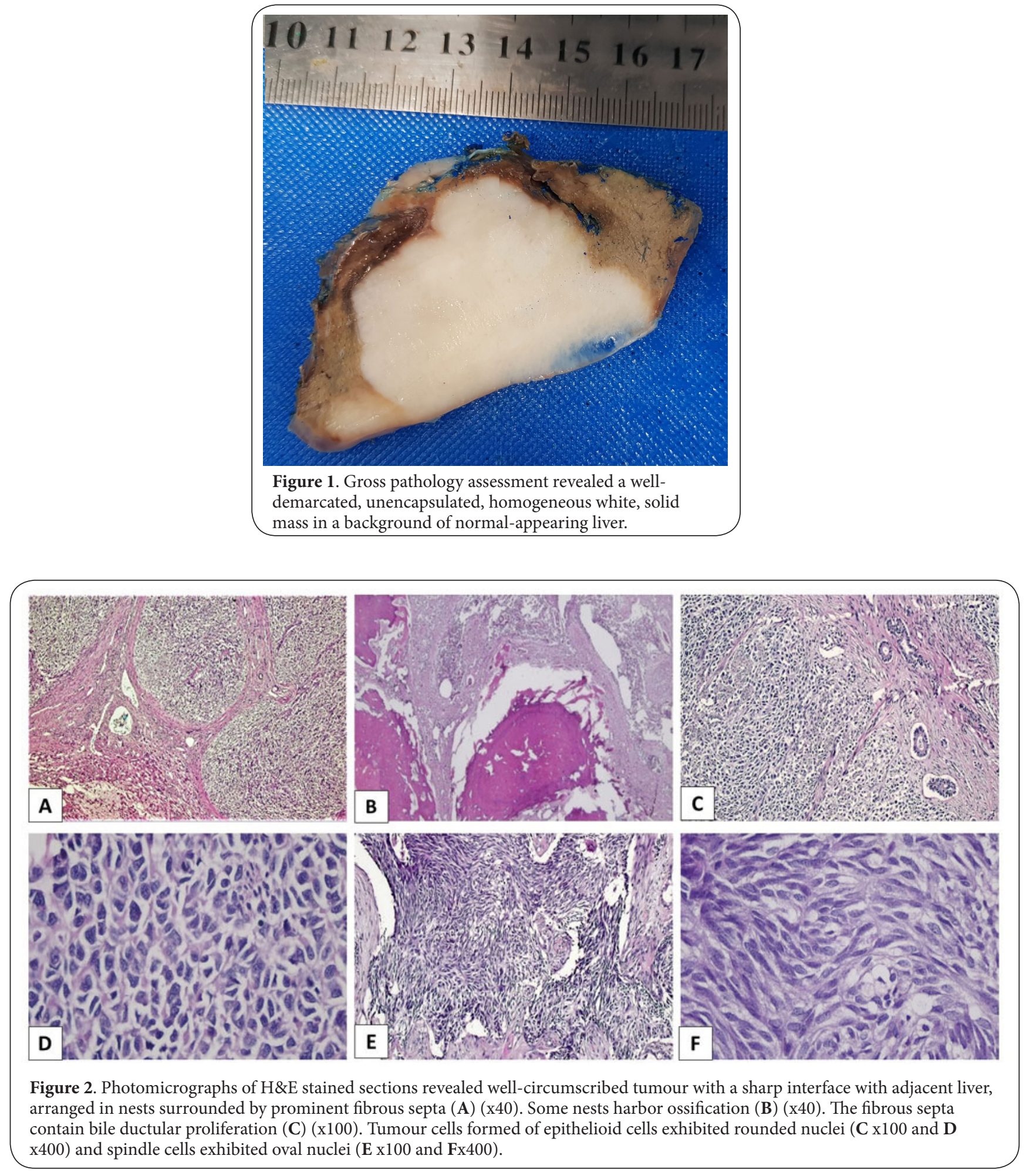


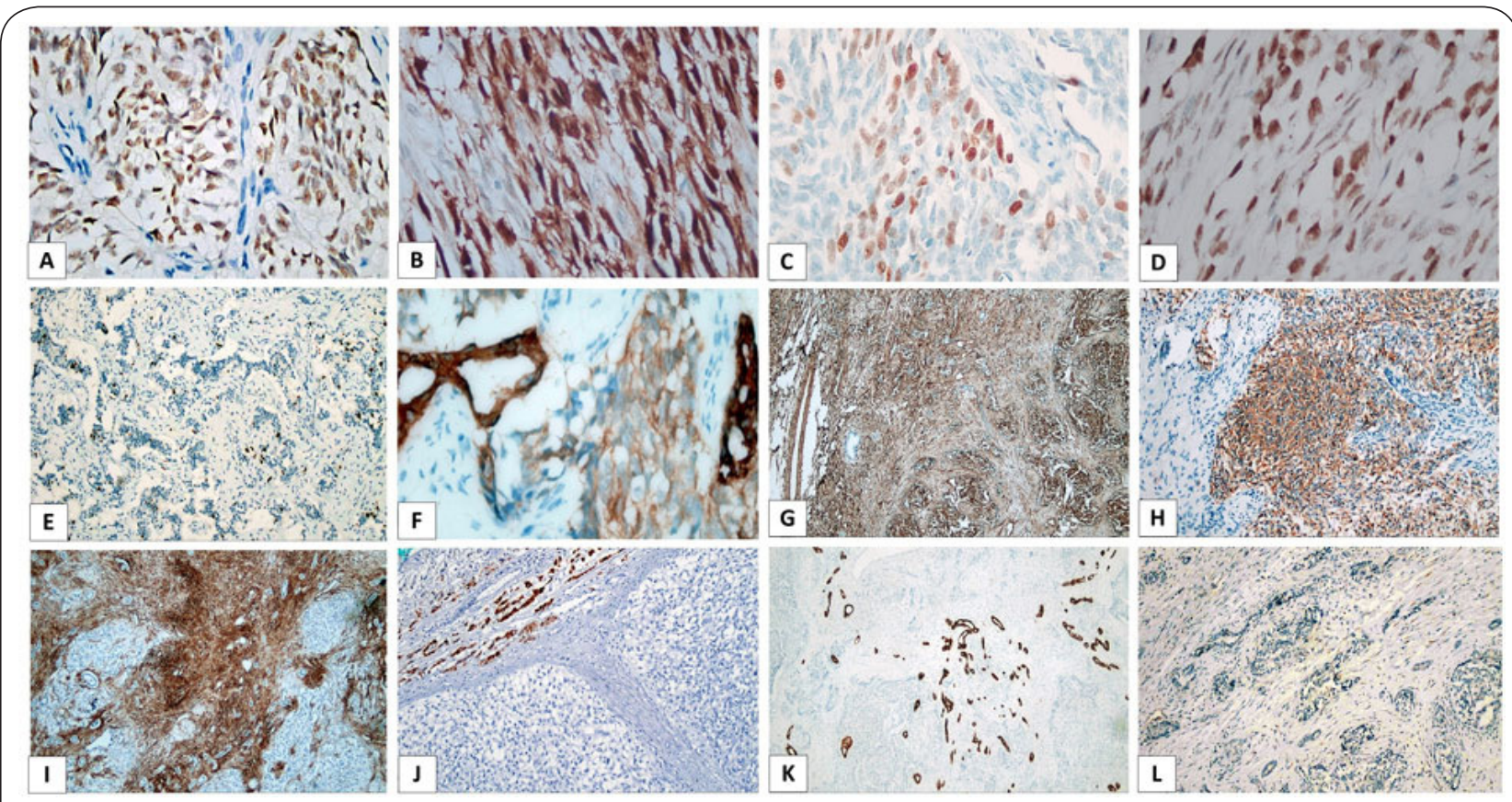

Figure 3. Photomicrographs of immunostained sections revealed tumour cells showed positive nuclear reaction for WT-1 (A) (x400), $\beta$-Catenin (B) (x400), PR (focally) (C) (x400), INI-1 (D) (x400) and a low proliferative index of Ki67 (E) (x40). Tumour cells showed cytoplasmic staining for CK (stronger intensity in bile ductules) (F) (x400), vimentin (stained stromal cells also) (G) (x40) and synaptophysin (H) (x100). Tumour cells are negative for SMA (stains the surrounding stromal cells) (I) (x40), HepPar-1 (stains the adjacent normal liver tissue) (J) (x100), CK7 (stains the bile ductules) (K) (x40), AFP, CD99, GFAP and chromogranin A (L) (x100).

levels in more than $90 \%$ of $\mathrm{HB}$ cases, positive immunstaining for AFP and HepPar-1 [13]. Small cell undifferentiated (SCUD) $\mathrm{HB}$ is, as CNSET, negative for AFP and HepPar-1 [14], however the increased proliferation index and the lost INI-1 expression may aid in the differential with CNSET [7].

Other differential diagnoses include biphasic synovial sarcoma (SS) and Desmoplastic small round cell tumour (DSRCT) [7]. Identifying the characteristic translocations of SS is helpful in distinguishing both tumours. WT1-EWS translocation, typically found in DSRCT, is lacking in CNSET cases [15].

Surgical resection is the currently adopted treatment modality for CNSET with proved to be curative in more than half of the reported cases [16]. The role of chemotherapy protocols used soft tissue sarcoma or $\mathrm{HB}$ is unclear whether of value in preventing tumour recurrence, additionally, neoadjuvant chemotherapy does not affect tumour size or necrosis in radiological findings or subsequent surgical specimens [17].

\section{Competing interests}

The authors declare that they have no competing interests.

\section{Authors' contributions}

\begin{tabular}{|l|c|c|c|}
\hline Authors' contributions & NM & BA & AE \\
\hline Research concept and design & $\checkmark$ & -- & -- \\
\hline Collection and/or assembly of data & $\checkmark$ & $\checkmark$ & -- \\
\hline Data analysis and interpretation & $\checkmark$ & -- & -- \\
\hline Writing the article & $\checkmark$ & -- & $\checkmark$ \\
\hline Critical revision of the article & -- & -- & $\checkmark$ \\
\hline Final approval of article & $\checkmark$ & $\checkmark$ & $\checkmark$ \\
\hline Statistical analysis & -- & -- & -- \\
\hline
\end{tabular}

\section{Publication history}

Editor: Khin Thway, The Royal Marsden Hospital, UK. Received: 12-Apr-2020 Final Revised: 06-June-2020 Accepted: 18-June-2020 Published: 26-June-2020

\section{References}

1. J. L. Hornick. Calcifyig Nested Stromal-Epithelial Tumour of the Liver. in WHO Classification of Tumours. Digestive System Tumours, 5 th., WHO Classification of Tumours Editorial Board, Ed. Lyon: IARC. 2019; 490-492.

2. K. Ishak, Z. Goodman and J. Stocker. Miscellaneous malignant tumors. in Tumors of the Liver and Intrahepatic Bile Ducts, Washington, DC: Armed Forces Institute of Pathology. 2001; 271-278.

3. Procopio F, Di Tommaso L, Armenia S, Quagliuolo V, Roncalli M and Torzilli G. Nested stromal-epithelial tumour of the liver: An unusual liver entity. World J Hepatol. 2014; 6:155-9. | Article | PubMed Abstract | PubMed FullText

4. Tsuruta S, Kimura N, Ishido K, Kudo D, Sato K, Endo T, Yoshizawa T, Sukeda A, Hiraoka N, Kijima $\mathrm{H}$ and Hakamada K. Calcifying nested stromal epithelial tumor of the liver in a patient with Klinefelter syndrome: 
Magdy et al., Journal of Histology \& Histopathology 2020,

http://www.hoajonline.com/journals/pdf/2055-091X-7-6.pdf

a case report and review of the literature. World J Surg Oncol. 2018; 16:227. | Article | PubMed Abstract | PubMed FullText

5. E. Fryer and R. Chetty. Unusual and rare tumours of the liver. Diagnostic Histopathol. 2012; 18:449-456.

6. Misra $S$ and Bihari $C$. Desmoplastic nested spindle cell tumours and nested stromal epithelial tumours of the liver. APMIS. 2016; 124:24551. | Article | PubMed

7. Benedict $M$ and Zhang X. Calcifying Nested Stromal-Epithelial Tumor of the Liver: An Update and Literature Review. Arch Pathol Lab Med. 2019; 143:264-268. | Article | PubMed

8. Geramizadeh B. Nested Stromal-Epithelial Tumor of the Liver: A Review. Gastrointest Tumors. 2019; 6:1-10. | Article | PubMed

9. Wang Y, Zhou J, Huang WB, Rao Q, Ma HH and Zhou XJ. Calcifying nested stroma-epithelial tumor of the liver: a case report and review of literature. Int J Surg Pathol. 2011; 19:268-72. | Article | PubMed

10. Heywood G, Burgart $L J$ and Nagorney DM. Ossifying malignant mixed epithelial and stromal tumor of the liver: a case report of a previously undescribed tumor. Cancer. 2002; 94:1018-22. | PubMed

11. Heerema-McKenney A, Leuschner I, Smith N, Sennesh J and Finegold MJ. Nested stromal epithelial tumor of the liver: six cases of a distinctive pediatric neoplasm with frequent calcifications and association with cushing syndrome. Am J Surg Pathol. 2005; 29:10-20. | Article | PubMed

12. Misra $S$ and Bihari $C$. Desmoplastic nested spindle cell tumours and nested stromal epithelial tumours of the liver. APMIS. 2016; 124:24551. | Article | PubMed

13. R. Saxena and A. Quaglia. Hepatoblastoma. in WHO Classification of Tumours. Digestive System Tumours, 5th ed., W. C. of T. E. Board, Ed. Lyon: IARC. 2019; 240-244.

14. Badve S, Logdberg L, Lal A, de Davila MT, Greco MA, Mitsudo S and Saxena R. Small cells in hepatoblastoma lack "oval" cell phenotype. Mod Pathol. 2003; 16:930-6. | Article | PubMed

15. Hill DA, Swanson PE, Anderson K, Covinsky MH, Finn LS, Ruchelli ED, Nascimento AG, Langer JC, Minkes RK, McAlister W and Dehner LP. Desmoplastic nested spindle cell tumor of liver: report of four cases of a proposed new entity. Am J Surg Pathol. 2005; 29:1-9. | Article | PubMed

16. Tehseen S, Rapkin L, Schemankewitz E, Magliocca JF and Romero R. Successful liver transplantation for non-resectable desmoplastic nested spindle cell tumor complicated by Cushing's syndrome. Pediatr Transplant. 2017; 21. | Article | PubMed

17. Assmann G, Kappler R, Zeindl-Eberhart E, Schmid I, Haberle B, Graeb C, Jung $A$ and Muller-Hocker J. beta-Catenin mutations in 2 nested stromal epithelial tumors of the liver--a neoplasia with defective mesenchymalepithelial transition. Hum Pathol. 2012; 43:1815-27. | Article | PubMed

\section{Citation:}

Magdy N, Ahmed B and Elwy A. Calcifying Nested Stromal-Epithelial Tumour of the Liver: case report and review of literature. J Histol Histopathol. 2020; 7:6. http://dx.doi.org/10.7243/2055-091X-7-6 